\title{
Fluid Containing Highly Branched Cyclic Dextrin: An Alternative Method to Enhance Endurance Exercise Performance
}

ISSN: 2577-1914

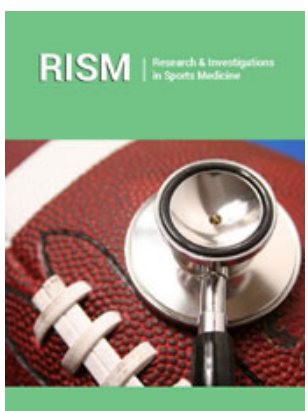

*Corresponding author: Nattiporn Nokkaew, Faculty of Sports Science, Chulalongkorn University, Bangkok, Thailand

Submission: 制 March 21, 2020

Published: 鍽June 02, 2020

Volume 6 - Issue 4

How to cite this article: Nokkaew $\mathrm{N}$ Srihirun K. Fluid Containing Highly Branched Cyclic Dextrin: An Alternative Method to Enhance Endurance Exercise Performance. Res Inves Sports Med, 6(4): RISM.000641. 2020 DOI: $10.31031 /$ RISM.2020.06.000641

Copyright@ Nokkaew N, This article is distributed under the terms of the Creative Commons Attribution 4.0 International License, which permits unrestricted use and redistribution provided that the original author and source are credited.
Nokkaew $\mathrm{N}^{*}$ and Srihirun $\mathrm{K}$

Faculty of Sports Science, Chulalongkorn University, Thailand

\section{Introduction}

It has been widely established that the ingestion of carbohydrate ( $\mathrm{CHO}$ ) pre-, during and post-exercise can improve exercise performance in intense events that lasting longer than 60 to 90 minutes.CHO provides most of the energy for high-intensity endurance exercise $(85 \%$ to $100 \% \mathrm{VO}_{2 \max }$ ] [1], maintains blood glucose, and possibly spares endogenous glycogen stores [2]. Consequently, $\mathrm{CHO}$ supplementation could be appropriate for athletes competing in endurance events. Fluid intake is a one frequent way to deliver CHO before, during and after exercise. However, the disadvantages of CHO-beverage are the monosaccharide and disaccharide composition which making the beverage very sweet [1] and the rate of gastric emptying and intestinal absorption are too slow compare to other form of $\mathrm{CHO}$ [3].

Table 1: Gastric emptying time of the test solutions.

\begin{tabular}{|c|c|c|}
\hline & & Gastric emptying time (SEM) (min) \\
\hline Solution & & $12.8(1.3)^{\mathrm{af}}$ \\
\hline Water & & $8.4(0.6)^{\mathrm{a}}$ \\
\hline NaCl & $5 \%$ ) & $20.4(3.0)^{\mathrm{be}}$ \\
\hline Glucose & $10 \%$ & $39.9(4.7)^{\mathrm{c}}$ \\
\hline Maltose & $5 \%$ & $16.2(1.9)^{\mathrm{bfh}}$ \\
\hline & $10 \%$ & $31.2(2.8)^{\mathrm{d}}$ \\
\hline Sucrose & $5 \%$ & $14.9(2.0)^{\mathrm{bfh}}$ \\
\hline & $10 \%$ & $24.4(3.3)^{\mathrm{eg}}$ \\
\hline Dextrin (DE16) & $5 \%$ & $12.1(1.4)^{\mathrm{eh}}$ \\
\hline & $10 \%$ & $17.3(2.1)^{\mathrm{bfh}}$ \\
\hline HBCD & $5 \%$ & $18.8(2.0)^{\mathrm{ef}}$ \\
\hline & $10 \%$ & $26.7(2.6)^{\mathrm{dg}}$ \\
\hline Sports drink based on & & $17.0(2.0)^{\mathrm{bfh}}$ \\
\hline $10 \%$ HBCD & & $21.9(2.0)^{\mathrm{eg}}$ \\
\hline $10 \%$ dextrin (DE16) & & \\
\hline
\end{tabular}

Note: Adapted from Takii $\mathrm{H}$ et al. [3].

Data represent means \pm SEM for 10 subjects. Values that do not share common superscript letters are significantly different at $\mathrm{p}<.05$.

Highly branched cyclic dextrin (HBCD) is a new type of maltodextrin, produced from waxy corn starch by the cyclization reaction of a branching enzyme (EC 2.4.1.18) [4-6]. HBCD has a high molecular weight and narrower molecular weight distribution than other maltodextrins. It is highly soluble in water and the solution is stable during storage, does 
not have an unfavorable smell or taste in solution and has low osmotic pressure which is a key factor to determine the gastric emptying rate (GER) of a beverage [7]. As a result of its low osmotic pressure, drinks containing HBCD have a shorter gastric emptying rate than glucose-based drink and maltodextrin-based drinks [3] and less gastrointestinal disorders in humans during exercise [8]. Therefore, athletes who consume HBCD may possibly proceed the exercise comfortably with little fatigue (Table 1).

HBCD can improve endurance exercise performance by supplying glucose energy for a longer period. The effect of HBCD on endurance exercise can be seen from the study of Furuyashiki et al. [9] which investigated the effect of HBCD and maltodextrin on blood glucose concentration and the rating of perceived exertion (RPE) during endurance exercise in a crossover, double-blind study of healthy volunteers. The participants consumed HBCD or maltodextrin $(15 \mathrm{~g})$ dissolved in $200 \mathrm{ml}$ distilled water then consumed the other 2 weeks later. The participants immediately started exercise using bicycle ergometer. The study was found that blood glucose concentration after ingestion tended to be higher in ingesting HBCD than maltodextrin and the rate of perceived exertion (RPE) tended to be lower after HBCD administration than maltodextrin [9]. The effect of HBCD was consistent with the study from Shiraki et al. [7]. Shirakiet et al. [7] examined the effects of HBCD administration on endurance performance in elite swimmers. The subjects received either HBCD, glucose $(1.5 \mathrm{~g} / \mathrm{kg}$ body weight) or water (a control) and followed by 10 cycles of intermittent swimming. When consuming HBCD, the time to fatigue was $70 \%$ longer than consuming glucose and water. In Addition, plasma glucose in the HBCD group was maintained at higher level during pre-swimming cycles than in the glucose or water group [7]. These results indicate that HBCD supplementation can enhances athletic endurance performance during exercise.

\section{Conclusion}

HBCD, a new type of maltodextrin, can play an important role in supplementation strategies for athletes. HBCD administration has been observed to enhance endurance exercise performance. An administration from $15 \mathrm{~g}$ to $1.5 \mathrm{~g} / \mathrm{kg}$ body weight was used to lower RPE, maintain blood glucose level and prolong the time to fatigue. However, the mechanism for lower RPE after HBCD ingestion is yet still unknown. Further study is required to provide more information regarding the mechanism for lower PRE after HBCD administration.

\section{References}

1. Malfatti C, Laat ED, Soler L, Bronkhorst I, Pacheco C, et al (2011) Maltodextrin's effect on the performance of elite mountain biking athletes during simulated competition and on power output at the ventilatory threshold. Human Movement 12(3): 232-236.

2. Too BW, Cicai S, Hockett KR, Applegate E, Davis BA, et al. (2012) Natural versus commercial carbohydrate supplementation and endurance running performance. Journal of the International Society of Sports Nutrition 9(27).

3. Takii H, Takii Nagao Y, Kometani T, Nishimura T, Nakae T, et al. (2005) Fluids containing a highly branched cyclic dextrin influence the gastric emptying rate. International Journal of Sports Medicine 26(4): 314-319.

4. Choi SS, Danielewska-Nikiel B, Ohdan K, Kojima I, Takata H, et al. (2009) Safety evaluation of highly-branched cyclic dextrin and a 1,4-alphaglucan branching enzyme from Bacillus stearothermophilus. Regul Toxicol Pharmaco 55: 281-290.

5. Takata H, Ohdan K, Takaha T, Kuriki T, Okada S (2003) Properties of branching enzyme from hyperthermophilic bacterium, Aquifexaeolicus, and its potential for production of highly-branched cyclic dextrin. J Appl Glycosci 50: 15-20.

6. Takata H, Takaha T, Okada S, Hizukuri S, Takagi M, et al. (1996) Structure of the cyclic glucan produced from amylopectin by Bacillus stearothermophilus branching enzyme. Carbohydr Res 295: 91-101.

7. Shiraki T, Kometani T, YoShitani K, Takata H, Nomura T (2015) Evaluation of exercise performance with the intake of highly branched cyclic dextrin in athletes. Food Science and Technology Research 21(3): 499-502.

8. Takii H, Kometani T, Nishimura T, Kuriki T, Fushuki T (2004) A sports drink based on highly branched cyclic dextrin generates few gastrointestinal disorders in untrained men during bicycle exercise. Food Science and Technology Research 10(4): 428-431.

9. Furuyashik T, Tanimoto H, Yokoyama Y, Kitaura Y, Kuriki T (2014) Effects of ingesting highly branched cyclic dextrin during endurance exercise on rating of perceived exertion and blood components associated with energy metabolism. Bioscience, Biotechnology, and Biochemistry 78(12): 2117-2119. 